\title{
Abundance and distribution of antibiotic resistance genes in a full-scale anaerobic-aerobic system alternately treating ribostamycin, spiramycin and paromomycin production wastewater
}

\author{
Mei Tang $\cdot$ Xiaomin Dou $(\mathbb{D} \cdot$ Chunyan Wang $\cdot$ Zhe Tian $\cdot$ Min Yang $\cdot$ \\ Yu Zhang
}

Received: 16 February 2017/Accepted: 15 May 2017/Published online: 27 May 2017

(C) Springer Science+Business Media Dordrecht 2017

\begin{abstract}
The occurrence of antibiotic-resistant bacteria and antibiotic resistance genes (ARGs) has been intensively investigated for wastewater treatment systems treating single class of antibiotic in recent years. However, the impacts of alternately occurring antibiotics in antibiotic production wastewater on the behavior of ARGs in biological treatment systems were not well understood yet. Herein, techniques including high-capacity quantitative PCR and quantitative PCR (qPCR) were used to investigate the
\end{abstract}

Electronic supplementary material The online version of this article (doi:10.1007/s10653-017-9987-5) contains supplementary material, which is available to authorized users.

M. Tang · C. Wang $\cdot$ Z. Tian · M. Yang · Y. Zhang ( ()

State Key Laboratory of Environmental Aquatic

Chemistry, Research Center for Eco-Environmental

Sciences, Chinese Academy of Sciences, Beijing 100085,

China

e-mail: zhangyu@rcees.ac.cn

X. Dou $(\bowtie)$

College of Environmental Science and Engineering,

Beijing Forestry University, Beijing 100083, China

e-mail: douxiaomin@bjfu.edu.cn

C. Wang

Department of Biology and Chemical Engineering,

Nanyang Institute of Technology, Nanyang 473004,

China

M. Tang $\cdot$ Z. Tian $\cdot$ M. Yang $\cdot$ Y. Zhang

University of Chinese Academy of Sciences,

Beijing 100049, China behavior of ARGs in an anaerobic-aerobic full-scale system. The system alternately treated three kinds of antibiotic production wastewater including ribostamycin, spiramycin and paromomycin, which referred to stages 1, 2 and 3. The aminoglycoside ARGs (52.1-79.3\%) determined using high-capacity quantitative PCR were the most abundant species in all sludge samples of the three stages. The total relative abundances of macrolide-lincosamide-streptogramin (MLS) resistance genes and aminoglycoside resistance genes measured using qPCR were significantly higher $(P<0.05)$ in aerobic sludge than in sewage sludge. However, the comparison of ARGs acquired from three alternate stages revealed that MLS genes and the aminoglycoside ARGs did not vary significantly $(P>0.05)$ in both aerobic and anaerobic sludge samples. In aerobic sludge, one acetyltransferase gene (aacA4) and the other three nucleotidyltransferase genes ( $a a d B, a a d A$ and $a a d E)$ exhibited positive correlations with int $\mathrm{I} 1\left(r^{2}=0.83-0.94 ; P<0.05\right)$, implying the significance of horizontal transfer in their proliferation. These results and facts will be helpful to understand the abundance and distribution of ARGs from antibiotic production wastewater treatment systems.

Keywords Antibiotic production wastewater · Antibiotic resistance genes - Aminoglycoside resistance genes - Wastewater treatment systems . Alternate treatments 


\section{Introduction}

Antibiotic production wastewater usually contains extremely high concentrations of residual antibiotics and is an important reservoir of resistant genes even after the biological treatment. These residual antibiotics will inevitably release into aquatic and soil environments and influence the microflora (SidrachCardona et al. 2014; Yu et al. 2014; Zhang et al. 2013). Many studies have investigated antibiotic-resistant bacteria and ARGs from wastewater treatment systems treating single type of antibiotic production wastewater and revealed that the corresponding resistance genes exhibited high detectable frequencies and abundances (Li et al. 2010; Liu et al. 2012; Wang et al. 2015; Zhai et al. 2016; Zhang et al. 2013). However, one pharmaceutical factory alternately produced different kinds of antibiotics to meet the needs of markets. It results in the alternate discharge of different types of wastewater, and these wastewaters need to be treated in the same treatment plants. The alternate treatments of different types of antibiotic production wastewater may lead to an increase in the ARG types in activated sludge. However, to our knowledge, little has been done to evaluate the impacts of alternate treatments of antibiotic production wastewater on the behavior of ARGs in biological treatment systems.

Aminoglycosides could inhibit a wide range of bacteria, especially Gram-negative aerobic bacilli, staphylococci (Ramirez and Tolmasky 2010), which are produced mainly by submerged fermentation in China. Aminoglycosides bind to the bacterial $30 \mathrm{~S}$ ribosomal subunit and inhibit protein synthesis. Several mechanisms have been proposed for bacterial resistance to aminoglycoside antibiotics including modification of ribosomal protein or 16S rRNA (only resistant to streptomycin), impaired antibiotic intake and accumulation, efflux of antibiotics and enzyme modification of the amino or hydroxyl groups of aminoglycosides (Mingeot-Leclercq et al. 1999; Vakulenko and Mobashery 2003). Ben Said et al. detected many aminoglycoside-resistance genes, for instance, from enterococci from one hundred and fourteen waste and surface water samples (2015). However, the occurrence and abundance of aminoglycoside resistance genes in wastewater treatment plants for treating antibiotic production wastewater have not been investigated yet.
Macrolides, lincosamide and streptogramin are structurally diverse groups of antibiotics that have overlapping binding sites in the peptidyl transferase region of $23 \mathrm{~S}$ rRNA. Therefore, the mechanism of macrolide-lincosamide-streptogramin (MLS) resistance genes could be divided into three groups: (1) mutations of binding sites that are methylation of the ribosomal target of the antibiotics, (2) efflux of antibiotics and (3) inactivation of the antimicrobial substances (Roberts et al. 1999; Schönfeld and Kirst 2002). Recently the occurrence of MLS-resistant genes has received extensive attentions. Our previous study observed that the total relative abundance of MLS resistance genes (per 16S rRNA gene) in a pilotscale system was $2.5 \operatorname{logs}$ higher than that in sewage and inosine wastewater treatment systems (Liu et al. 2014). Luby et al. found that concentrations of ermB, erm $C$ and ermF were all $>10^{9}$ copies $\mathrm{g}^{-1}$ in manure from tylosin-treated swine (2016). Koike et al. surveyed the presence of rRNA methylase genes in swine feedlot environment and found that ermB, erm $C$ and ermF genes were $100 \%$ present in of manure of animals administrated with antibiotics (2010).

This study aimed to survey the occurrence, abundance and distribution of ARGs in a full-scale biological treatment system consisted of anaerobic, anoxic and aerobic compartments. This biological system alternately treated three types of antibiotic production wastewater including (1) ribostamycin, a kind of aminoglycoside antibiotic, (2) spiramycin, a kind of macrolide antibiotic, and (3) paromomycin, a kind of aminoglycoside antibiotic. The abundances of MLS, aminoglycoside resistance genes and mobile genetic elements (MGEs) were analyzed by high-capacity quantitative PCR in combination with quantitative PCR (qPCR). High-capacity quantitative PCR was used to reveal the general information of resistance genes, and qPCR was used to further confirm seven macrolide-lincosamide-streptogramin (MLS) resistance genes, nine aminoglycoside resistance genes and one mobile element (class 1 integron (int I1)).

\section{Materials and methods}

Water and sludge sampling

Water and sludge samples were collected from a fullscale wastewater treatment system alternately treating 
different types of antibiotic production wastewater, which was installed in Wuxi Fortune Pharmaceutical Co. Ltd, Wuxi City, China. The full-scale system consisted of sequential up-flow anaerobic sludge bed (UASB), anoxic reactor and aerobic reactor in serials (Fig. 1). The anaerobic system is independent, and the effluent from the anaerobic system entered into anoxic and aerobic system. Anoxic and aerobic were running in a push-flow manner, and aerobic sludge would return into the anoxic system. Due to the varied markets, this factory produced ribostamycin antibiotic (aminoglycoside antibiotic) from April 2013 to December 2013; then spiramycin antibiotic from January 2014 to February 2015; then paromomycin antibiotic (aminoglycoside antibiotic) from March 2015 to June 2015. Therefore, the treatment system alternately treated three types of antibiotic production wastewater during that period (Figure S1). Aerobic activated sludge samples from a sewage treatment plant in Beijing, China.

The operation of the wastewater treatment system was divided into three consecutive stages including (1) stage 1 , receiving ribostamycin production wastewater that lasted for 9 months, (2) stage 2, receiving spiramycin production wastewater for 13 months, and (3) stage 3, receiving paromomycin production wastewater for 4 months. The treatment system was operated from September 2012 to June 2015. Samples were collected from the wastewater treatment system and the sewage treatment in Beijing. These samples were used to investigate the occurrence, abundance and distribution of MLS and aminoglycoside resistance genes in sludge from the three stages. Biological replicated samples (2-4) were taken in for each stage with a total number of 18 . Two anaerobic and two aerobic sludge samples were collected on April 7, 2013, and April 17, 2013, during stage 1. Four anaerobic and four aerobic sludge samples were collected on January 15, May 6, December 4, 2014, and February 7, 2015, during stage 2. Three aerobic sludge samples were collected on March, April 1, and May 2, 2015, during stage 3 (Figure S1). Flow proportional $(24 \mathrm{~h})$ composite samples were collected using automatic samplers (SD900, HACH, Loveland, CO, USA), except for the sludge samples, which were collected three times per day and mixed together. Grab sludge samples were taken from the respective site during the sampling period. During the sampling period, the full-scale system was confirmed to be stable and no rainfall event was recorded. All collected samples were transferred into brown glass bottles, kept in icebox and then transported to laboratory.

Methods of chemical analysis

Indexes like $\mathrm{COD}_{\mathrm{Cr}}$, ammonia, total nitrogen and total phosphate were determined according to the National Standard Methods of China (Table S1, S2 and S3) (Wei 2002). The concentrations of spiramycin in wastewater and sludge were determined using ultra performance liquid chromatography tandem mass spectrometry (UPLC-MS/MS, Waters, USA) (Table S4) (Liu et al. 2014). The concentrations of paromomycin in sludge were determined according to residual antibacterial

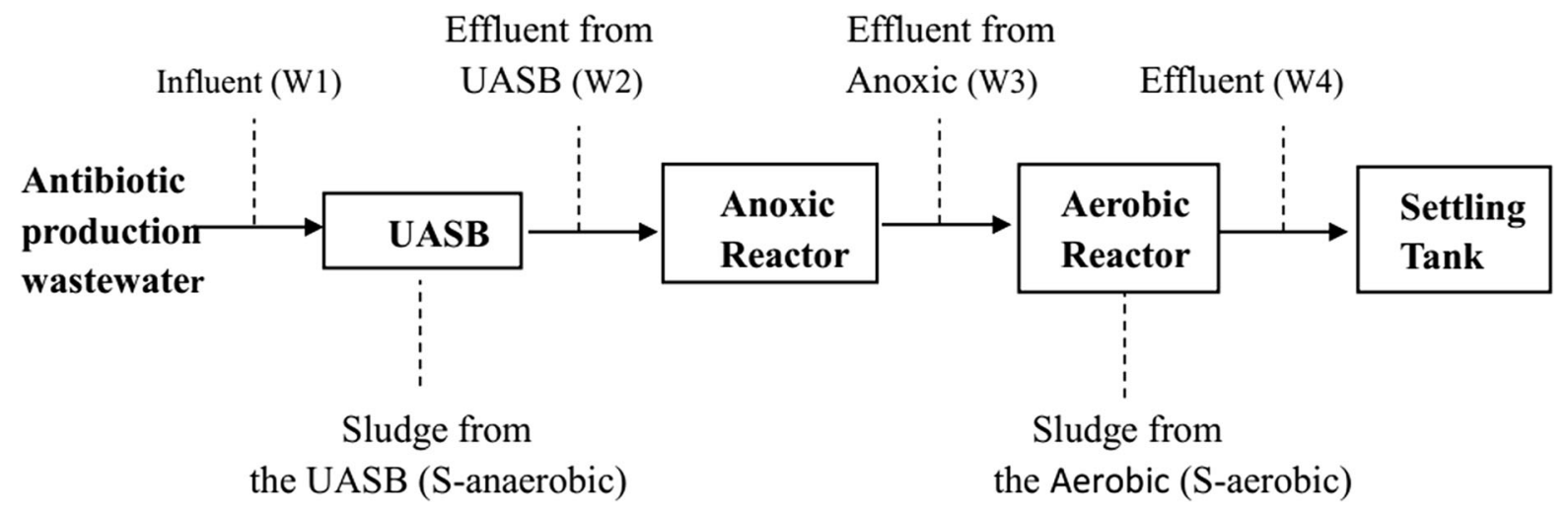

Fig. 1 Flow chart and sampling sites of the full-scale antibiotic production wastewater treatment systems. UASB up-flow anaerobic sludge bed reactor. $W 1=$ raw influent, $W 2=$ effluent from UASB, $W 3=$ effluent from anoxic reactor,

$W 4=$ effluent from aerobic reactor: $\mathrm{S}_{1 \text {-anaerobic }}-\mathrm{S}_{1 \text {-aerobic }} ; \mathrm{S}_{2-}$ anaerobic $-S_{2 \text {-aerobic }} ; S_{3 \text {-anaerobic }}-S_{3 \text {-aerobic }}$ : sludge samples from the three stages treating ribostamycin, spiramycin, paromomycin production wastewater, respectively 
potency using a real-time quantitative method (Zhang et al. 2015). The details are provided in Supplementary Information (A.1).

\section{DNA extraction}

For each sludge sample, $1 \mathrm{~mL}$ of mixed liquor was centrifuged at $12,000 \times \mathrm{g}$ for $10 \mathrm{~min}$ at $4{ }^{\circ} \mathrm{C}$. After centrifugation, $0.25 \mathrm{~g}$ sediment (wet weight) was used for DNA extraction by a FastDNA SPIN kit for soil (Qbiogene, Solon $\mathrm{OH}$ ). The DNA was eluted in a total volume of $80 \mu \mathrm{L}$. The purity and concentration of the eluted DNA were checked by NanoDrop ND-1000 (Wilmington, DE). Extracted DNA was also checked by gel electrophoresis on a $1 \%$ (weight/volume) agarose gel.

\section{High-capacity quantitative PCR}

High-capacity quantitative PCR with a total of 296 primers was performed to quantify ARGs and MGEs using the SmartChip qPCR system (Wafergen, Fremont, CA) according to reported procedures (Su et al. 2015; Wang et al. 2014; Zhu et al. 2013). Quality assurance/ quality control (QA/QC) was performed according to standard protocols provided by Wafergen Biosystems. The results were analyzed using the SmartChip qPCR Software (v2.7.0.1), and wells with multiple melting peaks and amplification efficiencies beyond the range of 1.8-2.2 were discarded. All qPCR reactions were performed in triplicate, and a threshold cycle $\left(C_{\mathrm{t}}\right)$ of 31 was used as the detection limit. Only those samples in which all three replicates exhibited amplification were regarded as positive. The mean $C_{\mathrm{t}}$ of the three replicates in each qPCR assay was used to calculate $\Delta C_{\mathrm{t}}$ values. The 2- $\Delta C_{\mathrm{t}}$ method (Schmittgen and Livak 2008), where $\Delta C_{\mathrm{t}}=\left(C_{\mathrm{t}}\right.$ (ARG) $-C_{\mathrm{t}}$ (16S rRNA gene) $)$, was used to calculate the relative abundances of the detected ARG in proportion to the $16 \mathrm{~S}$ rRNA gene in each sludge sample.

Qualitative PCR and SYBR Green qPCR amplification of MLS and aminoglycoside resistance genes and class I integrons

Fifteen MLS resistance genes including eight rRNA methylase genes (ermA, ermB, erm $C$, ermF, erm $G$, erm $Q$, erm $T$ and erm $X$ ), three efflux genes ( $m s r A$, $m s r D$ and $m e f A$ ), two esterase genes (ereA and ere B) and two phosphorylase genes ( $m p h A$ and $m p h B)$; fourteen aminoglycoside enzymatic modificatory resistance genes including six acetyltransferase genes (aac(3)-I, aac(3)-II, aac(3)-III, aac(3)-IV, aacA4 and $\left.\operatorname{aac}\left(6^{\prime}\right)-I e+\operatorname{aph}\left(2^{\prime \prime}\right)\right)$, three nucleotidyltransferase genes $(a a d B, a a d A$ and $a a d E)$ and five phosphotransferase genes (aph ( $\left.3^{\prime}\right)-I$, aphA1, aphA2, strA and strB); and one mobile elements (class 1 integron (int 1 )) were tested with primers listed in Table S5. The qualitative PCR assay was carried out for the sewage treatment plants and all sludge samples from the wastewater treatment systems, with sterile water used as the negative control. The qualitative PCR assay performed for MLS resistance genes was followed as described previously (Liu et al. 2014). PCR assay for aminoglycoside resistance genes was carried out in 25-uL volume reactions using an ABI PCR System 9700 (ABI, USA). The PCR mixture contained $1 \times$ Ex Taq buffer, $5 \mathrm{nM}$ dNTP, $0.625 \mathrm{U}$ Ex Taq (Takara, Japan), $400 \mathrm{nM}$ each primer, $0.5 \mathrm{mg} / \mathrm{mL}$ BSA and 1 to $2-\mu \mathrm{L}$ DNA. The temperature program consisted of initial denaturation at $95{ }^{\circ} \mathrm{C}$ for $5 \mathrm{~min}$, followed by 35 cycles of $30 \mathrm{~s}$ at $95^{\circ} \mathrm{C}, 30 \mathrm{~s}$ at different annealing temperatures (Table S5), and extension at $72{ }^{\circ} \mathrm{C}$ for $45 \mathrm{~s}$, followed by a final extension step at $72{ }^{\circ} \mathrm{C}$ for $7 \mathrm{~min}$. Amplification of investigated genes was checked by running PCR products on $1 \%$ (weight/volume) agarose gel in $1 \times$ TBE buffer. In qualitative PCR assay, seven MLS resistance genes (ermB, ermF, ermB, erm $G$, $m e f A$, ere $A$ and $m p h B$ ), nine aminoglycoside resistance genes (aac(3)-II, aacA4, aadA, aadB, aadE, aphA1, aphA2, strA and strB) and one mobile element (intI1) exhibited amplification.

These seven detected MLS resistance genes, one mobile element (intI1) and the 16S rRNA genes were quantified for all sludge samples using SYBR Green real-time PCR, as described previously (Liu et al. 2014). Nine detected aminoglycoside resistance genes were also quantified for all sludge samples using SYBR Green real-time PCR with the same primers used in qualitative PCR assay. Standard plasmids carrying target genes were obtained by TA clones and extracted using a TIANpure Mini Plasmid kit (Tiangen, China). Concentrations of the standard plasmids (ng $\mu \mathrm{L}^{-1}$ ) were determined with the Nanodrop ND1000 (Nanodrop, USA) and converted to copies $\mu \mathrm{L}^{-1}$ (Liu et al. 2014). The $25-\mu \mathrm{L}$ reactions typically contained $1 \times$ Sybr Green I, $1 \times$ Dye (Takara), $200 \mathrm{nM}$ each primer, $0.5 \mathrm{mg} / \mathrm{mL}$ BSA and $2-\mu \mathrm{L}$ DNA templates. Real-time PCR was run using an 
ABI 7300 apparatus (ABI, USA) following the program: $95{ }^{\circ} \mathrm{C}$ for $30 \mathrm{~s}, 40$ cycles consisting of: (1) $95{ }^{\circ} \mathrm{C}$ for $10 \mathrm{~s}$, (2) annealing temperature for $15 \mathrm{~s}$ (Table S5), (3) $72{ }^{\circ} \mathrm{C}$ for $15 \mathrm{~s}$ and (4) $78{ }^{\circ} \mathrm{C}$ for $26 \mathrm{~s}$ to collect the fluorescent signals. The melting process was automatically generated by the ABI 7300 software. All standards, samples and negative control (sterile water) were quantified in triplicates. To prevent the inhibition of the sample matrix, 10-100fold diluted samples were used for quantification. The following requirements were satisfied to obtain reliable quantification (Table S6): $R^{2}$ was higher than 0.99 for standard curves over five orders of magnitude. Amplification efficiencies based on slopes were between 90 and $110 \%$. The specificity was assured by the melting curves and gel electrophoresis. The minimum quantification limits for all genes were in the range of $1.0 \times 10^{2}-2.1 \times 10^{3}$ copies per $\mu \mathrm{L}$ DNA.

To minimize variances caused by different bacterial abundances, DNA extraction and aminoglycoside quantification efficiencies, the relative abundances of MLS and resistance genes and mobile elements were obtained by normalizing their copy numbers to those of the 16S rRNA genes (Table S11, S12). The relative abundances of MLS and aminoglycoside resistance genes and mobile elements (gene copies per $\mu \mathrm{g}$ DNA) are shown in Table (S13, S14).

\section{Statistical analyses}

All statistical analyses were performed using the package SPSS (version 15.0). Paired samples $t$ tests and $P$ values were used to assess significant differences between systems and samples. Pearson's bivariate correlation analysis was used to assess correlations between MLS resistance and aminoglycoside genes and mobile elements in sludge samples from the wastewater treatment systems. Significance tests were conducted by Monte Carlo permutation (999 times). Generally, in this manuscript, $P$ values $<0.05$ are regarded as significant.

\section{Results}

Chemical characteristics of wastewater and sludge

As shown in Tables S1-S3, the influent chemical oxygen demand (CODcr) was $1236-3599 \mathrm{mg} / \mathrm{L}$ in the biological system treating three types of antibiotics $\left(\mathrm{S}_{1}-\right.$ $\mathrm{S}_{3}$ ) and decreased to $452-1148 \mathrm{mg} / \mathrm{L}$ in the anaerobic unit and to $143-322 \mathrm{mg} / \mathrm{L}$ in the aerobic unit, respectively. The corresponding removal ratios were 63.4-68.1 and 88.4-94.3\%, respectively. The system removed $97.7-99.1 \%$ of $\mathrm{NH}_{3}{ }^{+}-\mathrm{N}$ and $87.5-94.7 \%$ of $\mathrm{SO}_{4}{ }^{2-}$, respectively. The effluent $\mathrm{pH}$ was relatively stable. The concentrations of spiramycin in aerobic sludge from $\mathrm{S}_{2 \text {-anaerobic }}, \mathrm{S}_{2 \text {-aerobic }}, \mathrm{S}_{3 \text {-anaerobic }}$ and $\mathrm{S}_{3 \text { - }}$ aerobic were $3.13 \pm 0.26,28.4 \pm 0.3,0.96 \pm 0.01$ and $3.29 \pm 0.09 \mathrm{mg} / \mathrm{kg}$ dry weight, respectively. The concentrations of paromomycin in $\mathrm{S}_{3 \text {-anaerobic }}$ and $\mathrm{S}_{3 \text {-aerobic }}$ were $427.5 \pm 12.0$ and $379 \pm 45.4 \mathrm{mg} / \mathrm{kg}$ dry weight, respectively (Table S4).

\section{Relative abundance of MLS and aminoglycoside resistance genes using high-capacity quantitative PCR}

Among the targeted ARGs, aminoglycoside resistance genes were dominant in all sludge samples of the three stages, accounting for 79.3, 78.6, 60.6, 52.1, 73.9 and $77.3 \%$ of the total abundance of ARGs in $\mathrm{S}_{1 \text {-aerobic }}, \mathrm{S}_{2-}$ aerobic, $S_{3 \text {-aerobic }}, S_{1 \text {-anaerobic }}, S_{2 \text {-anaerobic }}$ and $S_{3 \text {-anaerobic }}$, respectively (Fig. 2, Table $\mathrm{S} 7$ ). The aerobic sludge in the alternative three stages $\left(S_{1-\text { aerobic }}, S_{2 \text {-aerobic }}\right.$ and $S_{3-}$ aerobic) had 8, 9 and 14 kinds of aminoglycoside resistance genes and 9, 8 and 17 kinds of MLS resistance genes, respectively. Acetyltransferase gene aacA4 (1.55 normalized to bacterial 16S rRNA gene in average) and rRNA methylase genes ermB, ermF and $\operatorname{ermX}(0.13,0.07,0.07$ normalized to bacterial $16 \mathrm{~S}$ rRNA gene in average) exhibited the highest detected frequency (Table S9, S10).

As shown in Table S7 by high-capacity quantitative PCR, the total relative abundances of all detected ARGs normalized to bacterial 16S rRNA gene in aerobic sludge was $2.90,2.80$ and 1.60 for the three stages $\left(\mathrm{S}_{1 \text {-aerobic }}\right.$, treating ribostamycin production wastewater; $S_{2 \text {-aerobic }}$, treating spiramycin production wastewater; and $\mathrm{S}_{3 \text {-aerobic }}$, treating paromomycin production wastewater), respectively, whereas the relative abundance of all detected ARGs in aerobic sludge for urban sewage treatment system was 0.21 . The relative abundances aminoglycoside ARGs normalized to bacterial 16S rRNA gene of in aerobic sludge were $2.30,2.20$ and 0.97 for the three stages, respectively. The relative abundances of MLS 


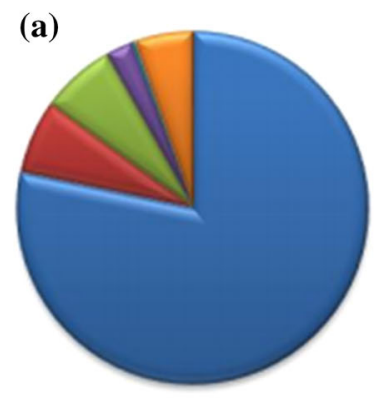

$S_{1-a e r o b i c}$

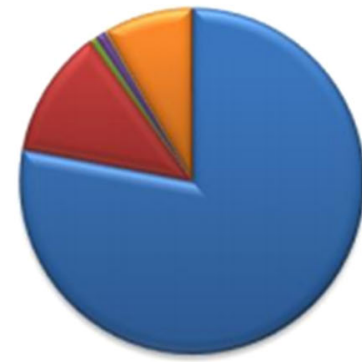

S2-aerobic
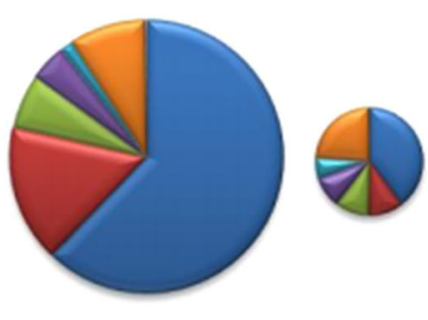

S3-aerobic $\square$ Aminoglycoside

$\square$ MLSB

$\square$ tetracycline

IFCA

$\square$ Beta Lactamase

$\square$ other/efflux

$\square$ Vancomycin

$\square$ sul

(b)

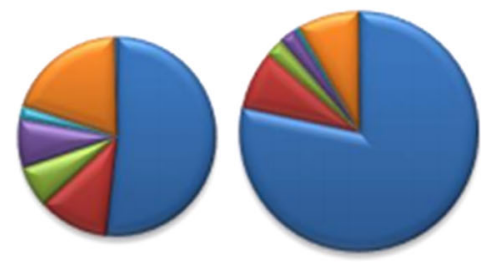

S1-anaerobic
S2-anaerobic

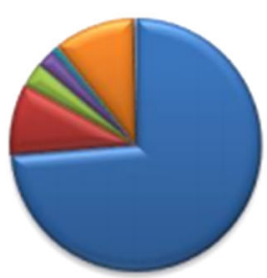

S3-anaerobic
Fig. 2 Relative abundance of antibiotic resistance genes by high-capacity quantitative PCR array. The resistance genes detected in sludge were classified based on the antibiotic to which they confer resistance. a The aerobic sludge during the three different stages $\left(S_{1}\right.$, treating ribostamycin production wastewater, $S_{2}$, treating spiramycin production wastewater, and $\mathrm{S}_{3}$, treating paromomycin production wastewater) and the sludge from urban wastewater treatment system. b The

resistance genes normalized to bacterial $16 \mathrm{~S}$ rRNA gene in aerobic sludge were $0.20,0.33$ and 0.25 for the three stages, respectively (Table S7). The ARGs detected in the full-scale wastewater treatment plant encompass the three major resistance mechanismsefflux pumps, antibiotic deactivation and cellular protection. The resistance mechanism of antibiotic deactivation exhibited the most abundance during the three treatment stages $\left(\mathrm{S}_{1 \text {-aerobic }}, 77.8 \%, \mathrm{~S}_{2 \text {-aerobic }}\right.$, $78.1 \%$ and $\mathrm{S}_{3 \text {-aerobic }}, 61.9 \% ; \mathrm{S}_{1-\text { anaerobic }}, 58.9 \%, \mathrm{~S}_{2-}$ anaerobic, $77.1 \%$ and $S_{3 \text {-anaerobic, }}$ 80.7\%) (Fig. 3).

The results showed that the total relative abundance of all detected ARGs was greater in the aerobic sludge $\left(\mathrm{S}_{1 \text {-aerobic }}, 2.90, \mathrm{~S}_{2 \text {-aerobic }}, 2.80, \mathrm{~S}_{3 \text {-aerobic }}, 1.60\right)$, but less in anaerobic sludge $\left(\mathrm{S}_{1 \text {-anarobic }}, 0.73, \mathrm{~S}_{2 \text {-anarobic }}\right.$, 0.96, $\mathrm{S}_{3 \text {-anarobic }}, 1.10$ ) (Table $\mathrm{S} 7$ ). The total relative abundance of MEGs was higher in aerobic sludge samples $\left(\mathrm{S}_{1 \text {-aerobic }}, 1.70, \mathrm{~S}_{2 \text {-aerobic }}, 1.50, \mathrm{~S}_{3 \text {-aerobic }}\right.$, 1.50) than those in anaerobic sludge samples $\left(\mathrm{S}_{1-}\right.$ anarobic, $1.2, \quad \mathrm{~S}_{2 \text {-anarobic, }} \quad 0.23, \mathrm{~S}_{3 \text {-anarobic }}, 0.21$ ) (Table S8). anaerobic sludge during the three different stages $\left(\mathrm{S}_{1}, \mathrm{~S}_{2}\right.$ and $\mathrm{S}_{3}$ ). FCA fluoroquinolone, quinolone, florfenicol, chloramphenicol and amphenicol resistance genes; MLSB macrolidelincosamide-streptogramin $B$ resistance genes. The pie chart area corresponds to the total relative abundance of ARGs in aerobic and anaerobic sludge, and take the first pie chart (S1aerobic) as a reference, and others are relative to the first pie chart

\section{The relative abundances of MLS and aminoglycoside resistance genes using SYBR Green qPCR}

Compared to the urban sewage treatment, all aerobic sludge samples from the three treatment stages contained significantly $(P<0.05)$ higher resistance genes (Fig. 4). ermX, ermF, ermB of MLS resistance genes and aacA4 of aminoglycoside resistance genes exhibited the highest detected frequency in the aerobic sludge samples from the three treatment stages (Fig. 4). When treating different kinds of antibiotics, the relative abundances of MLS and aminoglycoside resistance genes were very high, which may not significantly depend on the variety of the treated antibiotics. For example, in the second treatment stage $\left(\mathrm{S}_{2 \text {-aerobic }}\right.$, treating spiramycin production wastewater), the total relative abundance of MLS resistance genes was 0.059 normalized to bacterial 16S rRNA, which was not significantly different $(P>0.05)$ from the other two stage $\left(S_{1-\text { aerobic }}\right.$, treating ribostamycin 


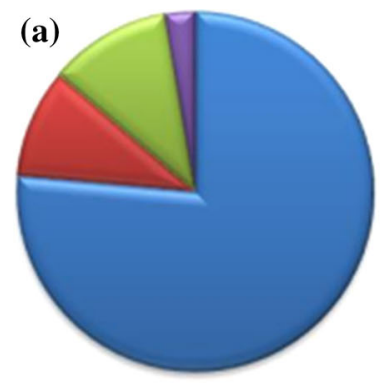

S1-aerobic

(b)

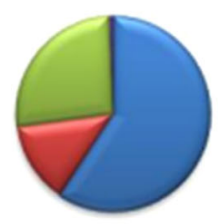

$S_{1-\text { anaerobic }}$

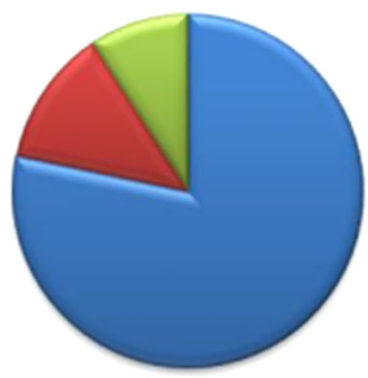

$S_{2}$-aerobic

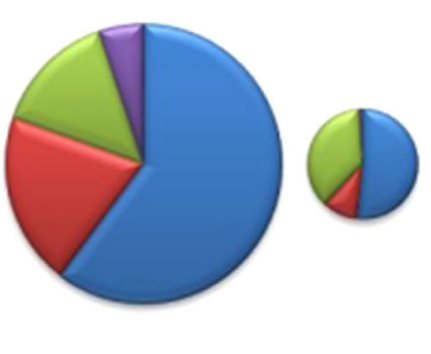

$\square$ antibiotic deactivation

$\square$ celluar production

⿶efflux-pumps

$\square$ others/unkonw

S3-aerobic Sewage sludge

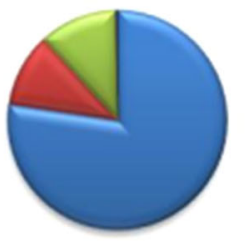

$S_{2}$-anaerobic

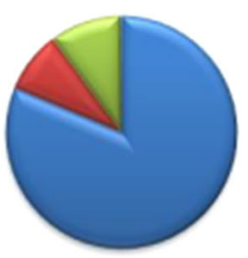

S3-anaerobic
Fig. 3 Relative abundance of antibiotic resistance genes is detected by high-capacity quantitative PCR arrays. The resistance genes detected in sludge were classified based on the mechanism of resistance. a The aerobic sludge during the three different stages ( $\mathrm{S} 1$, treating ribostamycin production wastewater, S2, treating spiramycin production wastewater, and S3, treating paromomycin production wastewater) and the sludge from urban wastewater system. b The anaerobic sludge

production wastewater, 0.067 normalized to bacterial $16 \mathrm{~S}$ rRNA; $\mathrm{S}_{3 \text {-aerobic }}$, treating paromomycin production wastewater, 0.046 normalized to bacterial 16S rRNA) (Table S11). The results showed that the total relative abundances of MLS and aminoglycoside resistance genes were higher in the aerobic sludge, but less in anaerobic sludge (Table S11, S12).

\section{Discussion}

The behavior of ARGs during the biological antibiotic wastewater treatment systems treating one kind of antibiotic or the combination of different kinds of antibiotic production wastewater has been reported previously as summarized in Table S15. However, to our knowledge, little has been done to evaluate the behavior of ARGs during wastewater treatment processes which alternately treated different kinds of antibiotic production wastewater. On the contrary to our expectation that the corresponding ARGs will reach the highest abundance when treating one type of antibiotic during the three different stages ( $\mathrm{S} 1$, treating ribostamycin production wastewater, S2, treating spiramycin production wastewater, and S3, treating paromomycin production wastewater). The pie chart area corresponds to the total relative abundance of ARGs in aerobic and anaerobic sludge, and take the first pie chart $\left(\mathrm{S}_{1 \text {-aerobic }}\right)$ as a reference, and others are relative to the first pie chart

production wastewater ( $\mathrm{Li}$ et al. 2010; Liu et al. 2012; Wang et al. 2015), the results of qPCR indicated that the MLS and aminoglycoside ARGs did not vary significantly $(P>0.05)$ when alternately treating different kinds of antibiotic wastewater (Fig. 5).

The total relative abundance of MLS and aminoglycoside resistance genes during the antibiotic production wastewater system was significantly higher than those in sewage treatment system. Similarly, our previous work found MLS resistance genes more abundant in a spiramycin wastewater treatment system than those reported in sewage treatment systems (Liu et al. 2014). Recently, a few studies were conducted to explore MLS and aminoglycoside resistance genes in environmental samples. Chen et al. discovered that the relative abundances of ermB, ermF, ermT and ermX were in the range of $4.4 \times 10^{-4}-5.4 \times 10^{-2}$ and $7.4 \times 10^{-5}-4.3 \times 10^{-1}$ in swine manures and lagoons, respectively (2007). Marti et al. reported that the relative abundance of $e r m B$ was at the magnitude of $10^{-4}-10^{-3}$ in the biofilm and sediments of a sewage treatment system (2013). Devarajan et al. found that 


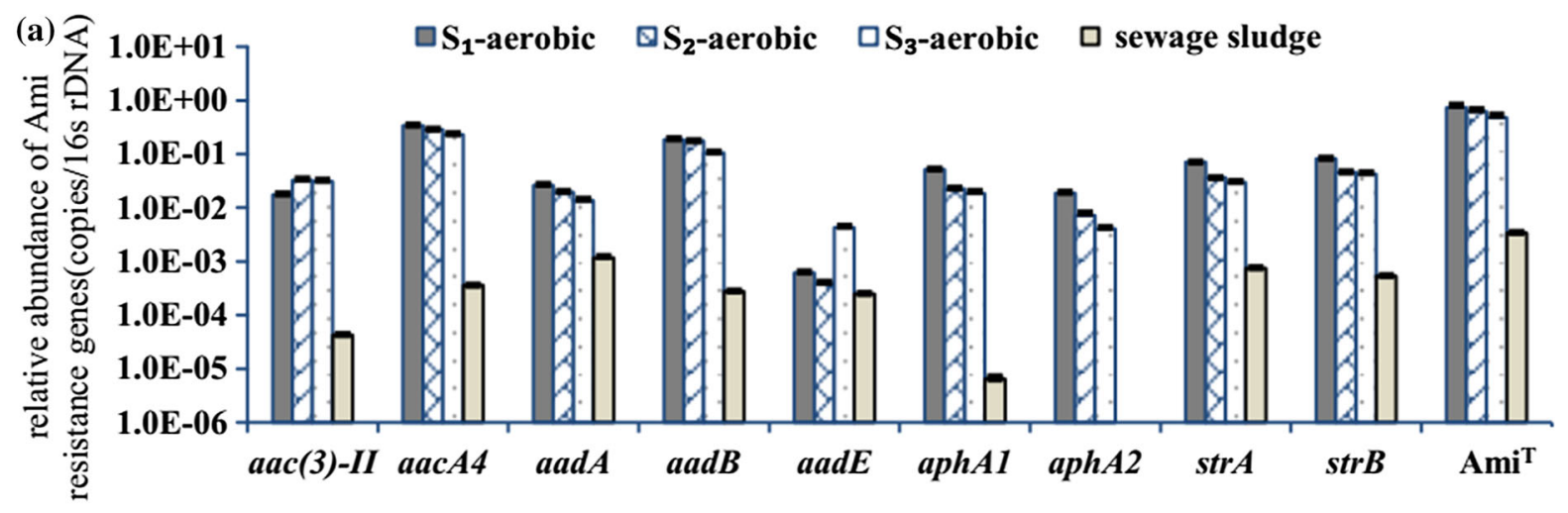

(b)

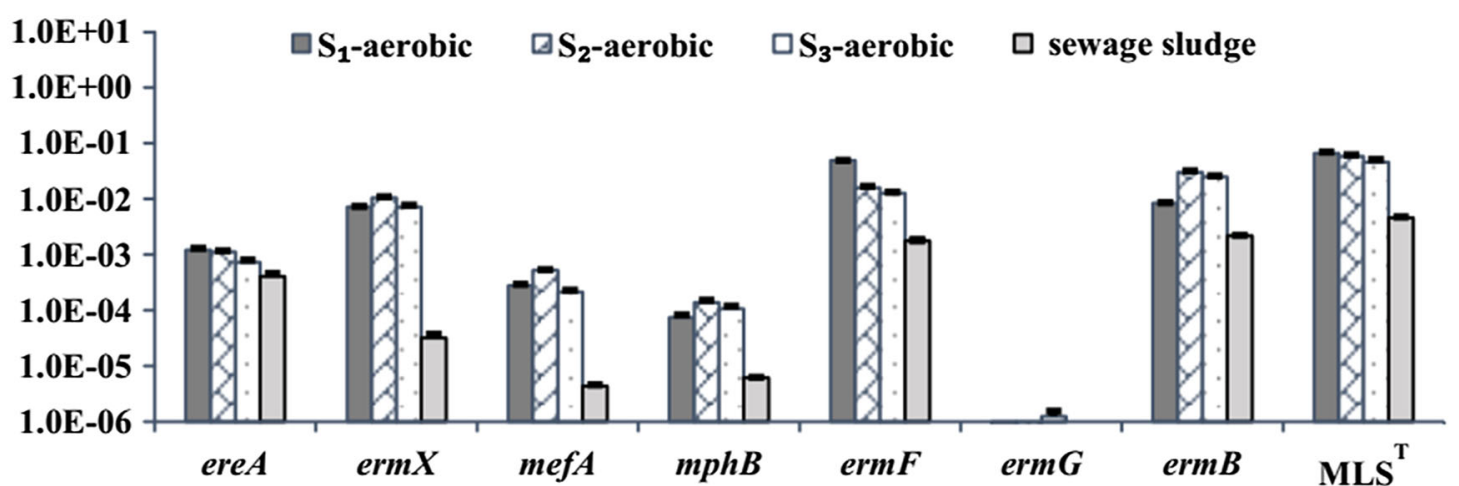

Fig. 4 Relative abundance of a aminoglycoside and b MLS resistance genes of qPCR in aerobic sludge of the full-scale antibiotic production wastewater treatment system during three

the relative abundance of aadA gene was $1.5 \times 10^{-5}$ $1.1 \times 10^{-3}$ in sediments samples collected from Lake Geneva (2015). In this study, the relative abundances of MLS and aminoglycoside resistance genes in the antibiotic production wastewater system were higher than those in the above mentioned systems.

A comprehensive profile of ARG subtypes in sludge samples from the antibiotic production wastewater treatment system was obtained in this study. In aerobic sludge, the most prominent ARG type found in the sludge samples from the three stages was all aminoglycoside resistance genes $\left(\mathrm{S}_{1 \text {-aerobic }}, 79.3 \%, \mathrm{~S}_{2-}\right.$ aerobic, $78.6 \%, \mathrm{~S}_{3 \text {-aerobic }}, 60.6 \%$ ), and the second most frequent genes were MLS resistance genes $\left(\mathrm{S}_{1 \text {-aerobic, }}\right.$ $\left.6.9 \%, \mathrm{~S}_{2 \text {-aerobic }}, 11.8 \%, \mathrm{~S}_{3 \text {-aerobic }}, 15.6 \%\right)$. The concentrations of aminoglycoside antibiotics in the aerobic sludge samples from the three stages were significantly higher than the concentrations of spiramycin antibiotics, which may be due to the reason that spiramycin antibiotic was more prone to different stages treating ribostamycin production wastewater $\left(\mathrm{S}_{1 \text {-aerobic }}\right)$, spiramycin production wastewater $\left(\mathrm{S}_{2 \text {-aerobic }}\right)$ and paromomycin production wastewater $\left(\mathrm{S}_{3 \text {-aerobic }}\right)$

biodegradation than aminoglycoside antibiotics (Chen et al. 2016; Topp et al. 2016). Aydin et al. investigated the behavior of ARGs during anaerobic sequencing batch reactors treating pharmaceutical wastewater that contained combinations of sulfamethoxazole-tetracycline-erythromycin (STE) and sulfamethoxazole-tetracycline (ST) and found that the concentration of tetracycline resistance genes was always higher than erythromycin resistance genes (2015). By employing high-capacity qPCR and qPCR, we demonstrated that acetyltransferase gene aacA4 was the most prevalent aminoglycoside resistance gene. Acetyltransferase gene aacA4 was probably the most clinically relevant acetyltransferase and often found in Gram-negatives (Ramirez and Tolmasky 2010). Fernández-Martínez et al. found that aacA4 was the most abundant resistance genes in clinical isolates of $E$. coli (2015). The second most frequent genes in the sludge samples from the three stages were MLS resistance genes. Both high-capacity qPCR and qPCR showed that rRNA 
(a)

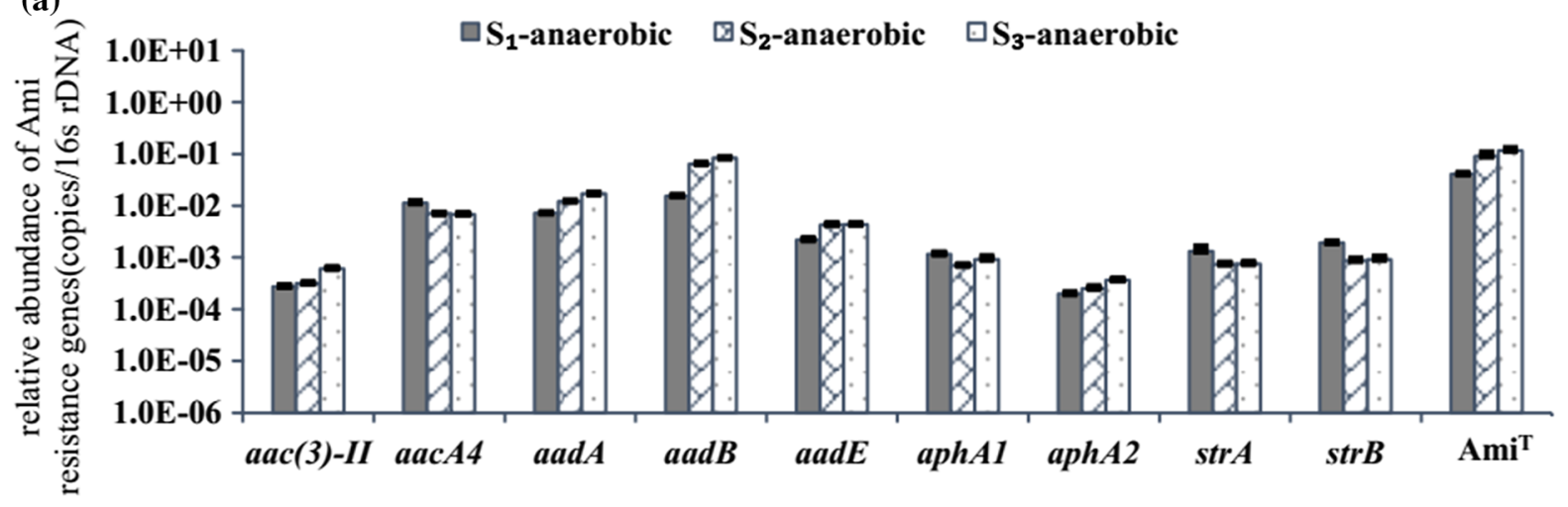

(b)

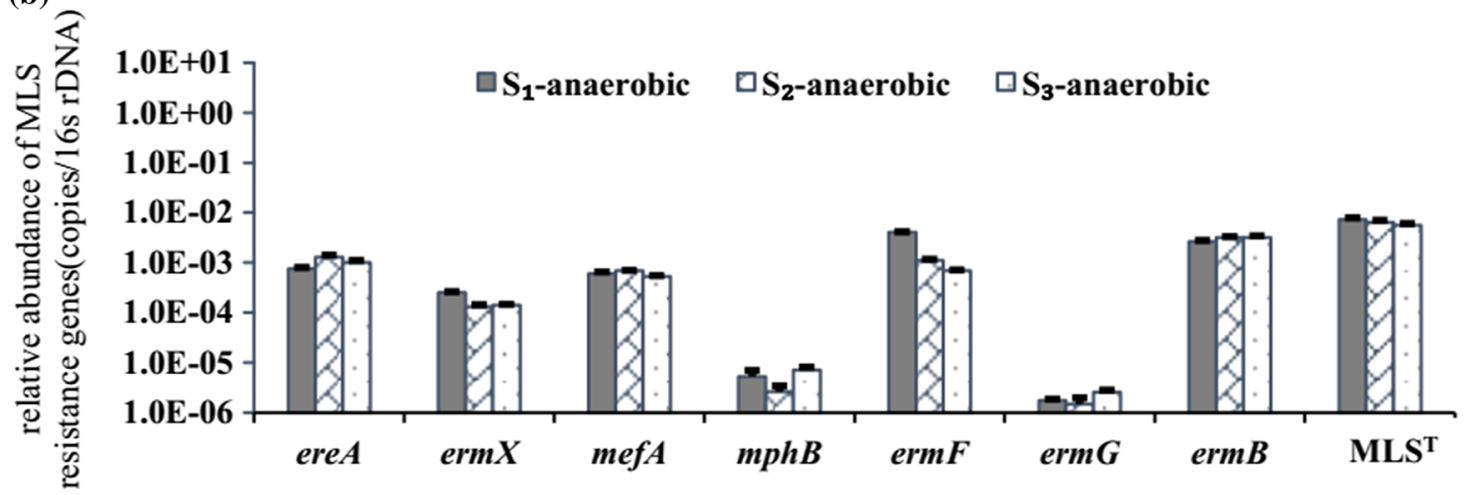

Fig. 5 Relative abundance of $\mathbf{a}$ aminoglycoside and b MLS resistance genes of qPCR in anaerobic sludge of the full-scale antibiotic production wastewater treatment system during three

methylase genes ermB, ermF and ermX were the most common MLS genes. Chen et al. (2007) and Koike et al. (2010) both found that $e r m B$ and $e r m F$ were the most abundant rRNA methylase genes in swine manure and lagoons $(2007,2010)$. Our previous study revealed that ermB, ermF and ermX were also the most abundant in the spiramycin wastewater treatment system (Liu et al. 2014).

The concentration of spiramycin in aerobic sludge was higher than that in anaerobic sludge, while the concentration of paromomycin in aerobic sludge was lower than that in anaerobic sludge. However, both of the corresponding MLS and aminoglycoside resistance genes exhibited higher relative abundance in aerobic sludge than those in anaerobic sludge, which might due to fewer bacterial hosts and mobile genetic elements for ARGs' proliferation (Ma et al. 2011; Tian et al. 2016; Liu et al. 2014). Harb et al. also reported different stages treating ribostamycin production wastewater $\left(\mathrm{S}_{1 \text {-anaerobic }}\right)$, spiramycin production wastewater $\left(\mathrm{S}_{2 \text {-anaerobic }}\right)$ and paromomycin production wastewater $\left(\mathrm{S}_{3 \text {-anaerobic }}\right)$

that lower ARG concentrations were over an order of magnitude lower in the anaerobic reactor sludge as compared to the aerobic system across all phases of operation (2016). It should be noted that due to the limited sample size, correlation relationship was not reliable. We will do this analysis in our future work.

Significant positive correlations were found between intI 1 and four aminoglycoside resistance genes (aacA4, aadA, $a a d B$ and $a a d E$ ) for aerobic sludge samples in the full-scale wastewater treatment system $\left(r^{2}=0.83,0.85,0.94\right.$ and $\left.0.94 ; P<0.05\right)$ (Table 1), indicating the important roles of intI 1 in their proliferation. intI1, which integrates and transfers ARGs via gene cassettes, is the most prevalent mobile element in all kinds of environments (Gillings et al. 2008). The aacA4 gene is mostly found as a gene cassette within class 1 integrons (Ramirez and Tolmasky 2010), and we also found that aacA4 gene 
Table 1 Correlation of ARGs with intIl in aerobic sludge samples from the antibiotic production wastewater treatment system

\begin{tabular}{lc}
\hline Resistance genes $^{\mathrm{a}}$ & intI $^{\mathrm{a}}$ \\
\hline aac(3)-II & -0.288 \\
aacA4 & $0.833^{*}$ \\
aadA & $0.853^{*}$ \\
aadB & $0.938^{* *}$ \\
aadE & $0.943^{* *}$ \\
aphA1 & 0.593 \\
aphA2 & 0.733 \\
strA & 0.517 \\
strB & 0.288 \\
ereA & 0.102 \\
ermX & 0.787 \\
mefA & 0.280 \\
mphB & -0.045 \\
ermF & 0.411 \\
ermG & -0.605 \\
ermB & -0.193 \\
\hline
\end{tabular}

* Numbers denote statistically significant correlations, $P<0.05$ (Pearson coefficient, bivariate analysis)

** Numbers denote statistically significant correlations, $P<0.01$ (Pearson coefficient, bivariate analysis)

${ }^{a}$ Units of resistance genes or intI1 used in correlation analysis are gene copies per $16 \mathrm{~S}$ rDNA genes

cassette exists in intI1 (results not shown). The aadA and $a a d B$ genes are also widely distributed as a gene cassette in intI1 (Ramirez and Tolmasky 2010).

\section{Conclusions}

In this study, the comprehensive profile of ARG subtypes was investigated in a full-scale biological wastewater treatment system with anaerobic and aerobic units alternately treating different kinds of antibiotics. The most prominent ARG type found in the sludge samples was all aminoglycoside ARG types. The wastewater treatment system produced significantly more ARGs than the sewage wastewater treatment system. MLS and aminoglycoside resistance genes did not vary significantly in aerobic and anaerobic sludge samples, suggesting that this wastewater treatment system was a complicate system. In aerobic sludge, one acetyltransferase genes (aacA4) and three nucleotidyltransferase genes ( $a a d B, a a d A$ and $a a d E)$ exhibited positive correlations with int I1, implying the significance of horizontal transfer in their proliferation. More work is needed to understand the mechanism of the ARGs behaviors in depth during alternately treating different types of antibiotics.

Acknowledgements This project is supported by National Natural Scientific Foundation of China (No. 21437005) and special fund of State Key Joint Laboratory of Environmental Simulation and Pollution Control (15L03ESPC).

\section{References}

Aydin, S., Ince, B., \& Ince, O. (2015). Development of antibiotic resistance genes in microbial communities during longterm operation of anaerobic reactors in the treatment of pharmaceutical wastewater. Water Research, 83, 337-344.

Ben Said, L., Klibi, N., Lozano, C., Dziri, R., Ben Slama, K., Boudabous, A., et al. (2015). Diversity of enterococcal species and characterization of high-level aminoglycoside resistant enterococci of samples of wastewater and surface water in Tunisia. Science of the Total Environment, 530-531, 11-17.

Chen, J., Ying, G. G., Wei, X. D., Liu, Y. S., Liu, S. S., Hu, L. X., et al. (2016). Removal of antibiotics and antibiotic resistance genes from domestic sewage by constructed wetlands: Effect of flow configuration and plant species. Science of the Total Environment, 571, 974-982.

Chen, J., Yu, Z., Michel, F. C., Wittum, T., \& Morrison, M. (2007). Development and application of real-time PCR assays for quantification of erm genes conferring resistance to macrolides-lincosamides-streptogramin B in livestock manure and manure management systems. Applied and Environmental Microbiology, 73(14), 4407-4416.

Devarajan, N., Laffite, A., Graham, N. D., Meijer, M., Prabakar, K., Mubedi, J. I., et al. (2015). Accumulation of clinically relevant antibiotic-resistance genes, bacterial load, and metals in freshwater lake sediments in Central Europe. Environmental Science and Technology, 49(11), 6528-6537.

Fernandez-Martinez, M., Miro, E., Ortega, A., Bou, G., Gonzalez-Lopez, J. J., Oliver, A., et al. (2015). Molecular identification of aminoglycoside-modifying enzymes in clinical isolates of Escherichia coli resistant to amoxicillin/clavulanic acid isolated in Spain. International Journal of Antimicrobial Agents, 46(2), 157-163.

Gillings, M., Boucher, Y., Labbate, M., Holmes, A., Krishnan, S., Holley, M., et al. (2008). The evolution of class 1 integrons and the rise of antibiotic resistance. Journal of Bacteriology, 190(14), 5095-5100.

Harb, M., Wei, C. H., Wang, N., Amy, G., \& Hong, P. Y. (2016). Organic micropollutants in aerobic and anaerobic membrane bioreactors: Changes in microbial communities and gene expression. Bioresource Technology, 218, 882-891.

Koike, S., Aminov, R. I., Yannarell, A. C., Gans, H. D., Krapac, I. G., Chee-Sanford, J. C., et al. (2010). Molecular ecology of macrolide-lincosamide-streptogramin B methylases in 
waste lagoons and subsurface waters associated with swine production. Microbial Ecology, 59(3), 487-498.

Li, D., Yu, T., Zhang, Y., Yang, M., Li, Z., Liu, M. M., et al. (2010). Antibiotic resistance characteristics of environmental bacteria from an oxytetracycline production wastewater treatment plant and the receiving river. Applied and Environmental Microbiology, 76(11), 3444-3451.

Liu, M., Ding, R., Zhang, Y., Gao, Y., Tian, Z., Zhang, T., et al. (2014). Abundance and distribution of Macrolide-Lincosamide-Streptogramin resistance genes in an anaerobicaerobic system treating spiramycin production wastewater. Water Research, 63, 33-41.

Liu, M., Zhang, Y., Yang, M., Tian, Z., Ren, L., \& Zhang, S. (2012). Abundance and distribution of tetracycline resistance genes and mobile elements in an oxytetracycline production wastewater treatment system. Environmental Science and Technology, 46(14), 7551-7557.

Luby, E. M., Moorman, T. B., \& Soupir, M. L. (2016). Fate and transport of tylosin-resistant bacteria and macrolide resistance genes in artificially drained agricultural fields receiving swine manure. Science of the Total Environment, 550, 1126-1133.

Ma, Y., Wilson, C. A., Novak, J. T., Riffat, R., Aynur, S., Murthy, S., et al. (2011). Effect of various sludge digestion conditions on sulfonamide, macrolide, and tetracycline resistance genes and class I integrons. Environmental Science and Technology, 45(18), 7855-7861.

Marti, E., Jofre, J., \& Balcazar, J. L. (2013). Prevalence of antibiotic resistance genes and bacterial community composition in a river influenced by a wastewater treatment plant. PLOS ONE, 8(10), 1-8.

Mingeot-Leclercq, M. P., Glupczynski, Y., \& Tulkens, P. M. (1999). Aminoglycosides: Activity and resistance. Antimicrobial Agents and Chemotherapy, 43(4), 727-737.

Ramirez, M. S., \& Tolmasky, M. E. (2010). Aminoglycoside modifying enzymes. Drug Resistance Updates: Reviews and Commentaries in Antimicrobial and Anticancer Chemotherapy, 13(6), 151-171.

Roberts, M. C., Sutcliffe, J., Courvalin, P., Jensen, L. B., Rood, J., \& Seppala, H. (1999). Nomenclature for macrolide and macrolide-lincosamide-streptogramin B resistance determinants. Antimicrobial Agents and Chemotherapy, 43(12), 2823-2830.

Schmittgen, T. D., \& Livak, K. J. (2008). Analyzing real-time PCR data by the comparative CT method. Nature Protocols, 3(6), 1101-1108.

Schönfeld, W., \& Kirst, H. A. (2002). Macrolide antibiotics (pp. 281-305). Berlin: Springer Basel AG.

Sidrach-Cardona, R., Hijosa-Valsero, M., Marti, E., Balcazar, J. L., \& Becares, E. (2014). Prevalence of antibiotic-resistant fecal bacteria in a river impacted by both an antibiotic production plant and urban treated discharges. The Science of the Total Environment, 488-489, 220-227.
Su, J. Q., Wei, B., Ou-Yang, W. Y., Huang, F. Y., Zhao, Y., Xu, H. J., et al. (2015). Antibiotic resistome and its association with bacterial communities during sewage sludge composting. Environmental Science and Technology, 49(12), 7356-7363.

Tian, Z., Zhang, Y., Yu, B., \& Yang, M. (2016). Changes of resistome, mobilome and potential hosts of antibiotic resistance genes during the transformation of anaerobic digestion from mesophilic to thermophilic. Water Research, 98, 261-269.

Topp, E., Renaud, J., Sumarah, M., \& Sabourin, L. (2016). Reduced persistence of the macrolide antibiotics erythromycin, clarithromycin and azithromycin in agricultural soil following several years of exposure in the field. Science of the Total Environment, 562, 136-144.

Vakulenko, S. B., \& Mobashery, S. (2003). Versatility of aminoglycosides and prospects for their future. Clinical Microbiology Reviews, 16(3), 430-450.

Wang, J. L., Mao, D. Q., Mu, Q. H., \& Luo, Y. (2015). Fate and proliferation of typical antibiotic resistance genes in five full-scale pharmaceutical wastewater treatment plants. Science of the Total Environment, 526, 366-373.

Wang, F. H., Qiao, M., Su, J. Q., Chen, Z., Zhou, X., \& Zhu, Y. G. (2014). High throughput profiling of antibiotic resistance genes in urban park soils with reclaimed water irrigation. Environmental Science and Technology, 48(16), 9079-9085.

Wei, F. S. (2002). Monitoring and analysis methods of water and wastewater, 4th ed. (pp. 210-213). Beijing: China Environmental Science Press.

Yu, X., Zuo, J., Li, R., Gan, L., Li, Z., \& Zhang, F. (2014). A combined evaluation of the characteristics and acute toxicity of antibiotic wastewater. Ecotoxicology and Environmental Safety, 106, 40-45.

Zhai, W. C., Yang, F. X., Mao, D. Q., \& Luo, Y. (2016). Fate and removal of various antibiotic resistance genes in typical pharmaceutical wastewater treatment systems. Environmental Science and Pollution Research, 23(12), 12030-12038.

Zhang, Y., Xie, J., Liu, M., Tian, Z., He, Z., van Nostrand, J. D., et al. (2013). Microbial community functional structure in response to antibiotics in pharmaceutical wastewater treatment systems. Water Research, 47(16), 6298-6308.

Zhang, H., Zhang, Y., Yang, M., \& Liu, M. (2015). Evaluation of residual antibacterial potency in antibiotic production wastewater using a real-time quantitative method. Environmental Science Processes and Impacts, 17(11), 1923-1929.

Zhu, Y. G., Johnson, T. A., Su, J. Q., Qiao, M., Guo, G. X., Stedtfeld, R. D., et al. (2013). Diverse and abundant antibiotic resistance genes in Chinese swine farms. Proceedings of the National Academy of Sciences of the United States of America, 110(9), 3435-3440. 